\title{
Impacts of climate change on hydrological processes in the Tibetan Plateau: a case study in the Lhasa River basin
}

\author{
Wenfeng Liu ${ }^{1,2} \cdot Z^{2}$ ongxue $\mathrm{Xu}^{2} \cdot$ Fapeng $\mathrm{Li}^{2,3} \cdot$ Lanying Zhang ${ }^{2} \cdot \mathrm{Jie} \mathrm{Zhao}^{2} \cdot$ \\ Hong Yang ${ }^{1,4}$
}

Published online: 3 April 2015

(c) Springer-Verlag Berlin Heidelberg 2015

\begin{abstract}
Climate change has great impacts on hydrological processes worldwide. The Tibetan Plateau (TP), the "Water Tower" of Asia, poses significant influences on Asian climate and is also one of the most sensitive areas to climate change. Therefore, it is of importance to investigate the plausible future hydrological regimes in the TP based on the climate scenarios provided by General Circulation Models (GCMs). In this study, the Variable Infiltration Capacity model was coupled with Shuffled Complex Evolution developed at the University of Arizona to explore the responses of hydrological processes to climate change in the Lhasa River basin, the tributary of the Yarlung Zangbo River in the southern TP. A downscaling framework based on Automatic Statistical Downscaling was used to generate the future climate data from two GCMs (Echam5 and Miroc3.2_Medres) under three scenarios (A1B, A2 and B1) for the period of 2046-2065. Results show increases for both air temperature and annual precipitation in the future climate. Evaporation, runoff and streamflow will experience a rising trend, whereas spring snow cover will reduce dramatically. These changes present significant spatial and
\end{abstract}

Wenfeng Liu

wenfeng.liu@eawag.ch

1 Eawag, Swiss Federal Institute of Aquatic Science and Technology, Ueberlandstrasse 133, 8600 Dübendorf, Switzerland

2 Key Laboratory of Water and Sediment Sciences, Ministry of Education, College of Water Sciences, Beijing Normal University, Beijing 100875, China

3 Development Research Center of the Ministry of Water Resources of P.R. China, Beijing 100038, China

4 Faculty of Sciences, University of Basel, Petersplatz 1, 4003 Basel, Switzerland temporal variations. The alteration of hydrological processes may challenge the local water resource management. This study is helpful for policy makers to tackle climate change related issues in terms of mitigation and adaptation.

Keywords Climate change - GCMs - VIC model . Tibetan Plateau · Lhasa River

\section{Introduction}

Hydrological cycle is a linkage between available water resources and agriculture, ecosystems and social activities. There are significant impacts of climate change on hydrological processes, and then on water resources, agriculture, and ecosystems as well as human societies at different spatial and temporal scales (Brown and Funk 2008; Ju et al. 2013; Piao et al. 2010; Sivakumar 2011). Therefore, it is essential to investigate the responses of hydrological cycle for better understanding the potential impacts of climate change on earth system and human societies. It is a frontier area to quantitatively estimate the magnitude and scope of impacts of climate change on hydrological processes.

The Tibetan Plateau (TP) is the highest plateau in the world with an average elevation over $4000 \mathrm{~m}$ above the see level. It is called the "Water Tower" of Asia and the "Third Pole" of the Earth (Immerzeel et al. 2010b; Qiu 2008). In its vast area of about 2.3 million $\mathrm{km}^{2}$ (almost one fourth of China's area), the TP has sourced several most important river systems in Asia, including Yellow, Yangtze, Mekong, Yarlung Zangbo-Brahmaputra, Ganges, Indus, Salween, Tarim, etc., at the same time provided water resources for more than 1.4 billion people (over $20 \%$ of the world population, Immerzeel et al. 2010b). Duo to the complex terrain, distinctive landscape, and high 
altitude, the TP exerts great impacts on the formulation of Asian monsoon, even the global climate. Meanwhile, it is also one of the most sensitive areas to the global climate change (Bolch et al. 2012; Li et al. 2013; Liu et al. 2009; Sun et al. 2013; Wang et al. 2013; Wu et al. 2006; Xu et al. 2009; You et al. 2007). During the last several decades, climate in the TP has experienced dramatic spatial and temporal changes and variations, with average temperature increasing at a rate of $0.447{ }^{\circ} \mathrm{C}$ per decade from 1961 to 2001, and most of meteorological stations have recorded rising trends precipitation at the same period $(\mathrm{Xu}$ et al. 2008). The reference evapotranspiration was reported to decrease at a rate of $0.691 \mathrm{~mm} \mathrm{a}^{-1}$ from 1970 to 2009 (Xie and Zhu 2013). This change has significantly accelerated the hydrological dynamics and altered the land surface processes in terms of glacier retreat, permafrost degradation, and runoff variation (Barnett et al. 2005; Guo et al. 2012; Ji and Kang 2013; Kang et al. 2010; West 2008; Yao et al. 2010).

The Yarlung Zangbo River (YZR) is one of the most important international rivers in the TP. The land-use in the YZR basin did not change much during the last decades $(\mathrm{Li}$ et al. 2012). The climate change, however, is significant (You et al. 2007). Therefore, it offers an ideal site to investigate the climate change impacts without intensive intervention from human beings. In this study, the Lhasa River (LR) basin was selected as the case study area, which is the largest and most important tributary of the YZR (Guan et al. 1984). The LR basin is the political, economic and cultural center of Tibet, rendering its irreplaceable role in Tibet. But, the hydrological regimes and the climate change impacts in this region are still not fully reported ( $\mathrm{Li}$ et al. 2014; Prasch et al. 2011; Qiu et al. 2014), making it difficult to predict future available water resources. Therefore, it is significant to simulate the hydrological cycle based on distributed hydrological model and explore the plausible impacts of climate change for better water resources management and sustainable social development in Tibet.

In this study, the Variable Infiltration Capacity (VIC) model was coupled with the Shuffled Complex Evolution developed at the University of Arizona (SCE-UA) to simulate the hydrological processes at a resolution of $10 \times 10 \mathrm{~km}$. The future climate change conditions were formed by downscaling from two selected General Circulation Models (GCMs) under the A1B, A2, B1 scenarios of Special Report of Emission Scenarios (SRES) for the period of 2046-2065. Here, we mainly focused on five major variables: evaporation, soil moisture, spring snow cover, runoff and streamflow, which are also the primary water resources for agriculture, ecosystem, and domestic and industrial uses. By simulating the watershed hydrological processes and estimating the range of precipitation and temperature trends, the objective of this study is to analyze the impacts of climate change on those key hydrological elements, and further to analyze the implication of change on agriculture, ecosystem and human society in the middle of twenty-first century. The simulation results are expected to be served as reference for climate change mitigation and adaptation, and water resources management in this vulnerable region.

\section{Simulation framework}

The overall simulation framework is presented in Fig. 1. The Automatic Statistical Downscaling (ASD) model is used to downscale the GCMs outputs. Land-use, soil, and climate data are inputted into the VIC model to simulate hydrological processes. The SCE-UA will calibrate the model parameters automatically based on an objective function $(\mathrm{OBJ})$.

\subsection{Methodology description}

\subsubsection{The ASD model}

The ASD model was developed by Hessami et al. (2008) under the Matlab environment. It is a station-based statistical downscaling technique, which builds the relationship between observed climate variables and climate predictors at each station. In the ASD model, predictor selection is based on backward stepwise regression and partial correlation coefficients. The simulation of precipitation is conditional, in which two steps are involved: precipitation occurrence (PO) and precipitation amount (PA):

$P O_{j}=\alpha_{0 j}+\sum \alpha_{i j} p_{i j}$

$P A_{j}^{0.25}=\beta_{0 j}+\sum \beta_{i j} p_{i j}+e_{j}$

where $P O_{j}$ is the precipitation occurrence at station $j ; P A_{j}$ is the precipitation amount at station $j ; p_{i j}$ is the selected predictor at station $j ; \alpha_{i j}$ and $\beta_{i j}$ are model parameters for predictor $p_{i j}$; and $e_{j}$ is model error.

The simulation of temperature $(\mathrm{T})$ is unconditional. One step is needed:

$T_{j}=\gamma_{0 j}+\sum \gamma_{i j} p_{i j}+e_{j}$

where $T_{j}$ is the temperature at station $T_{j}$ and $\gamma_{i j}$ is model parameter for predictor $p_{i j}$.

\subsubsection{The VIC model}

The VIC model is a large-scale semi-distributed land surface model (Liang et al. 1994; Liang and Xie 2001). It simulates the soil-vegetation-atmosphere interactive dynamics with 


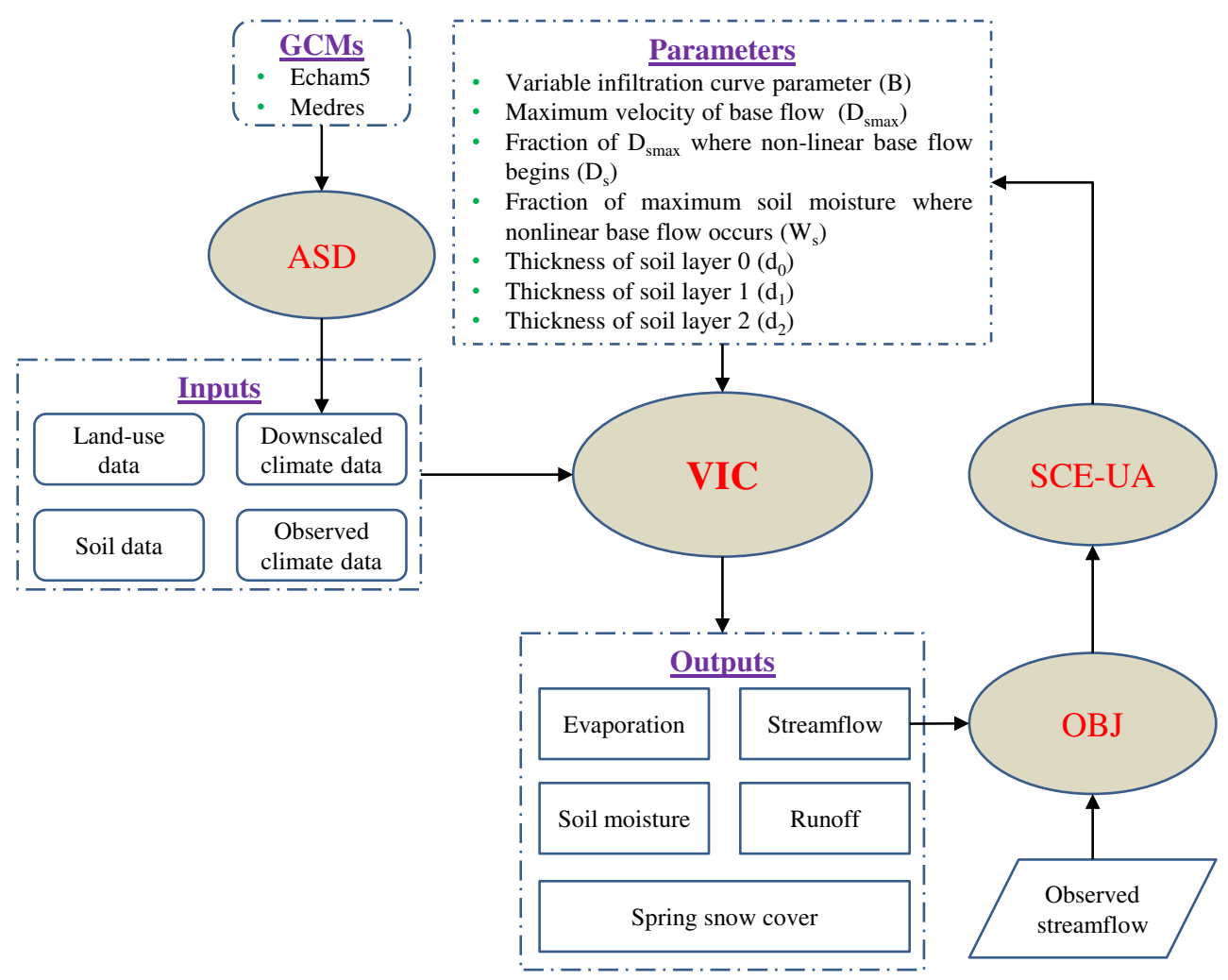

Fig. 1 Flowchart of the simulation framework

the function of climate, vegetation, and soil properties based on experimental algorithms. A wide range of physical processes are included in the model: precipitation interception, evaporation, infiltration, snow accumulation and melt, and runoff generation, etc. For runoff generation, the VIC model is able to consider two different runoff mechanisms: saturation excess runoff and infiltration excess runoff (Xie et al. 2003). It employs a spatially varying infiltration capacity strategy to represent sub-grid scale heterogeneity of soil properties used in Xinanjiang model (Zhao 1992), and can consider the spatial variability of precipitation and landuse (Liang et al. 1996a). More details on the VIC model can be found in Liang et al. (1994) and Liang and Xie (2001). Additionally, the land surface processes are modeled at each grid separately, making it easy to integrate with the GCMs output (Liang et al. 1996b). Since its development, the VIC model has been applied widely to simulate the hydrological processes and investigate the impacts of climate change at the regional or global scales (Hostetler et al. 2000; Liu et al. 2009; Sridhar et al. 2012).

\subsubsection{Calibration and assessment criteria}

Generally, seven parameters (see Fig. 1) related to soil characteristics in VIC are sensitive to local study area which should be calibrated carefully. However, no automatic calibration algorithms are integrated with the VIC model. In this study, a Matlab-based program was developed to search the optimal parameters by combining the VIC executable file and SCE-UA algorithm. The SCEUA algorithm was first developed by Duan et al. (1993), and then widely used for parameters optimization (Duan et al. 1994). The optimal parameters were obtained by minimizing OBJ (Viney et al. 2009), which was calculated from simulated daily streamflow against observation. The OBJ is expressed as:

$$
\begin{aligned}
& \text { OBJ }=\left(1-E_{n s}\right)+5\left|\ln \left(1+E_{r}\right)\right|^{2.5} \\
& E_{n s}=\frac{\sum\left(Q_{i, o}-\bar{Q}_{o}\right)^{2}-\sum\left(Q_{i, s}-Q_{i, o}\right)^{2}}{\sum\left(Q_{i, o}-\bar{Q}_{o}\right)^{2}} \\
& E_{r}=\frac{\sum Q_{i, s}-\sum Q_{i, o}}{\sum Q_{i, o}} \times 100 \%
\end{aligned}
$$

in which $E_{n s}$ is the Nash-Sutcliffe coefficient of efficiency; $E_{r}$ is the relative error; $Q_{i, o}$ and $Q_{i, s}$ are observed and simulated streamflow at the ith day; $\bar{Q}_{o}$ is the average of observed streamflow. This objective function is more flexible since it considers both the Nash-Sutcliffe coefficient of efficiency and the relative error.

Coefficient of determination $\left(\mathrm{R}^{2}\right)$ and root mean square deviation (RMSD) were used to assess the ASD model. $\mathrm{R}^{2}$ and RMSD are calculated as: 
$R^{2}=\frac{\left(\sum\left(Q_{i, o}-\bar{Q}_{o}\right)\left(Q_{i, s}-\bar{Q}_{s}\right)\right)^{2}}{\sum\left(Q_{i, o}-\bar{Q}_{o}\right)^{2} \sum\left(Q_{i, s}-\bar{Q}_{s}\right)^{2}}$

$\operatorname{RMSD}=\sqrt{\frac{\sum\left(C_{o}-C_{s}\right)^{2}}{n}}$

in which $\bar{Q}_{s}$ is the average of simulated streamflow, $C_{o}$ and $C_{s}$ are the observed and simulated climate value, and $n$ is the number of observations. At the same time, four criteria were used to evaluate the VIC model performance: $E_{n s}$ and $E_{r}$, coefficient of correlation $(r)$, and $R^{2}$.

\subsection{Data description}

\subsubsection{Input data in the ASD model}

The ERA-40 re-analysis of meteorological observation data (Uppala et al. 2005) were used to build the ASD model for selecting the most relevant predictors and deriving the regression parameters at each station. Table 1 lists the predictors used in this study. More than 25 GCMs are commonly used to investigate the climate change. However, the performance of each model varies at a given region due to the differences in physical processes, parameterization, and grid resolution. How to choose a reliable model for local study should be carefully addressed (Casado and Pastor 2011; Fu et al. 2013; Trenberth 1997). Our previous study suggested that five models: namely Echam5, Miroc3.2_Hires, Miroc3.2_Medres (Medres hereafter), Echam4 and GFDL:CM21 are relatively more suitable in the YZR basin (Liu et al. 2013). Considering the data availability and the completeness of climate scenarios, Echam5 and Medres were selected in this study. The same predictors as ERA-40 from Echam5 and Medres were used for downscaling. Three representative $\mathrm{CO}_{2}$ emission scenarios (A1B, A2 and B1 of SRES) were used to represent a wide range of emission levels, in which $\mathrm{A} 2$ predicts high rate of greenhouse gas (GHG) emissions of 850 parts per

Table 1 Predictors used for developing the ASD model

\begin{tabular}{llll}
\hline No. & Predictors & No. & Predictors \\
\hline 1 & $300 \mathrm{hPa}$ specific humidity & 11 & $200 \mathrm{hPa}$ zonal velocity \\
2 & $400 \mathrm{hPa}$ specific humidity & 12 & $300 \mathrm{hPa}$ zonal velocity \\
3 & $500 \mathrm{hPa}$ specific humidity & 13 & $400 \mathrm{hPa}$ zonal velocity \\
4 & Precipitation & 14 & $500 \mathrm{hPa}$ zonal velocity \\
5 & Surface pressure & 15 & Surface zonal velocity \\
6 & $200 \mathrm{hPa}$ temperature & 16 & $200 \mathrm{hPa}$ meridional velocity \\
7 & $300 \mathrm{hPa}$ temperature & 17 & $300 \mathrm{hPa}$ meridional velocity \\
8 & $400 \mathrm{hPa}$ temperature & 18 & $400 \mathrm{hPa}$ meridional velocity \\
9 & $500 \mathrm{hPa}$ temperature & 19 & $500 \mathrm{hPa}$ meridional velocity \\
10 & Surface temperature & 20 & Surface meridional velocity \\
\hline
\end{tabular}

million by volume (ppmv) by 2100 , while A1B as medium rate of $720 \mathrm{ppmv}$ and $\mathrm{B} 1$ as low rate of $550 \mathrm{ppmv}$ (IPCC 2000). The combination of two GCMs and three emission scenarios forms six scenarios: Echam5 A1B, Echam5 A2, Echam5, B1, Medres A1B, Medres A2 and Medres B1.

\subsubsection{Input data in the VIC model}

Inputs for the VIC model mainly include climate, soil and land-use data. Climate data (daily precipitation, daily maximum and minimum temperature) were obtained from six meteorological stations in or around the LR basin (Fig. 2), which were provided by China Meteorological Data Sharing Service System. This dataset covers a period of 1974-2000, with the first 2-years data being used for model warming-up. The station-based data were then interpolated to each grid by applying the Inverse Distance Weighted (IDW) method. In order to reduce the influence of complicated terrain of TP on the interpolation, a declination of $0.65^{\circ}$ per $100 \mathrm{~m}$ was adopted to the interpolation of maximum and minimum temperature ( $\mathrm{Li}$ et al. 2003). The soil parameters were derived from the global $5^{\prime}$ soil date offered by the NOAA hydrology office using the method described in Su and Xie (2003). Land-use data are $1 \mathrm{~km}$ global land cover provided by the University of Maryland. Both soil data and land cover data were resampled to the resolution of $10 \times 10 \mathrm{~km}$.

\subsubsection{Streamflow data}

Daily streamflow dataset in Lhasa hydrological station provided by Tibet Bureau of Hydrology and Water Resources was used for calibrating model parameters and validating model performance. This dataset covers a period of 1976-2000, in which data from 1976 to 1990 were used for model calibration, and the rest for model validation.

\section{The VIC model performance}

The model performance results are documented in Table 2 . When the meteorological observed data were used as model inputs, the relative error is low ( $2 \%)$ and the estimated flow process matches well with the observed process in terms of $E_{n s}, r$ and $R^{2}$, which are 0.94, 0.97 and 0.94, respectively. Additionally, the calibrated VIC model reproduced the observed flow satisfactorily when the independent climate data were used in the validation period. The $E_{r}$ falls in the range of $10 \%$, and the values for $E_{n s}$, $r$ and $R^{2}$ are $0.92,0.96$ and 0.93 , respectively. Figure 3 presents the comparison between the monthly simulated and observed flow for both calibration and validation periods. Results show that the observed and simulated 
Fig. 2 The study area and locations of the meteorological stations

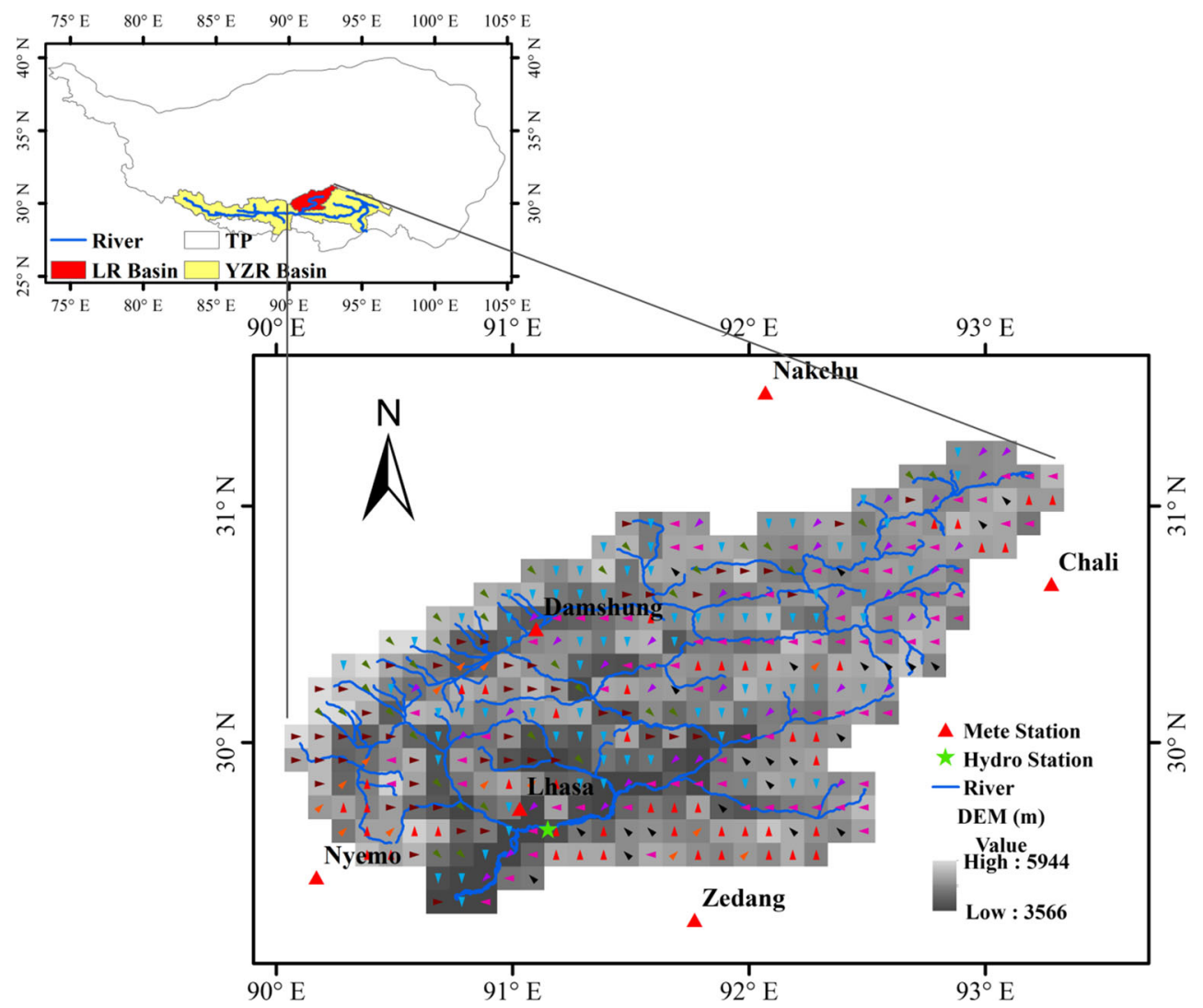

Table 2 Performance of the VIC model based on observation and GCMs outputs

\begin{tabular}{|c|c|c|c|c|c|c|c|c|}
\hline & \multicolumn{4}{|c|}{ Calibration } & \multicolumn{4}{|c|}{ Validation } \\
\hline & $\mathrm{E}_{\mathrm{r}}$ & $\mathrm{E}_{\mathrm{ns}}$ & $\mathrm{r}$ & $\mathrm{R}^{2}$ & $\mathrm{E}_{\mathrm{r}}$ & $\mathrm{E}_{\mathrm{ns}}$ & $\mathrm{r}$ & $\mathrm{R}^{2}$ \\
\hline Observation & 0.02 & 0.94 & 0.97 & 0.94 & 0.09 & 0.92 & 0.96 & 0.93 \\
\hline Echam5 & -0.04 & 0.63 & 0.83 & 0.68 & 0.05 & 0.71 & 0.85 & 0.72 \\
\hline Medres & -0.06 & 0.70 & 0.86 & 0.74 & 0.01 & 0.67 & 0.84 & 0.70 \\
\hline
\end{tabular}

streamflow is comparable, indicating the suitability of the VIC model in representing the flow process in the LR basin.

In the previous studies, the future climate data were directly inputted into hydrological models, which were generally calibrated with observed climate data, without justifying model performance by using the historical GCMs data (Liu et al. 2009). This implicitly assumes that the GCMs data have the comparable abilities in representing the hydrological processes as the measured meteorological data. The fact is, however, that the GCMs data do not always have such ability. Therefore, it is important to verify the historical GCMs outputs. In this study, the model performance was also investigated by using historical Echam5 and Medres outputs. Results indicate that the VIC model successfully represents the observed streamflow, with $E_{r}$ in $\pm 10 \%, E_{n s}$ larger than 0.63 , and $r$ exceeding 0.80 for both GCMs (Table 2; Fig. 3). The good performance of VIC using historical GCMs data as inputs further implies the fitness of Echam5 and Medres and success of the downscaling framework in the study area. On the basis of the reasonability of the historical downscaled data, it is expected that the future climate series are also suitable for investigating the impacts of climate change in the LR basin.

Figure 4 spatially describes the averaged values of five factors for the period of 1981-2000. Precipitation shows a dramatic spatial variation with a decreasing trend from $700.5 \mathrm{~mm}$ in the upstream (northeast part) to $357.1 \mathrm{~mm}$ in the downstream (southwest part). Evaporation does not change much with a narrow range of 172.1-269.9 mm for the whole basin. Soil shows the similar spatial distribution with precipitation, varying from 56.3 to $306.0 \mathrm{~mm}$. Spring snow cover is found at the upstream and some grids around the basin boundary. In contrast, grids in the middle- and down-stream do not show much spring snow cover. Runoff (including surface and subsurface runoff) shows a similar spatial pattern as soil moisture, but with a greater spatial variation of $505.1 \mathrm{~mm}$. Furthermore, the evaporation ratio (ratio of evaporation to precipitation) and runoff ratio (ratio of runoff to precipitation) were also explored in the whole basin (Fig. 5). Evaporation ratio 


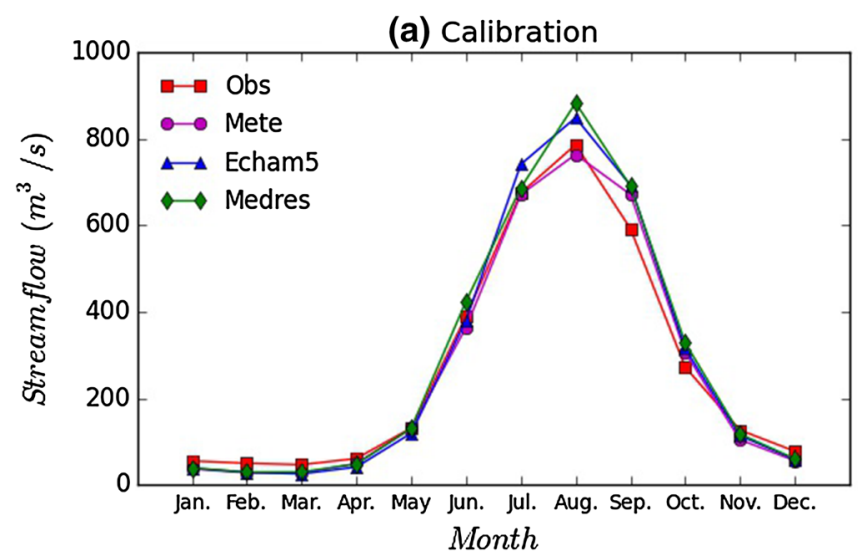

Fig. 3 Comparison between observed and simulated streamflow for the calibration and validation periods (Obs observed streamflow, Mete simulated streamflow based on meteorological climate data, Echam5

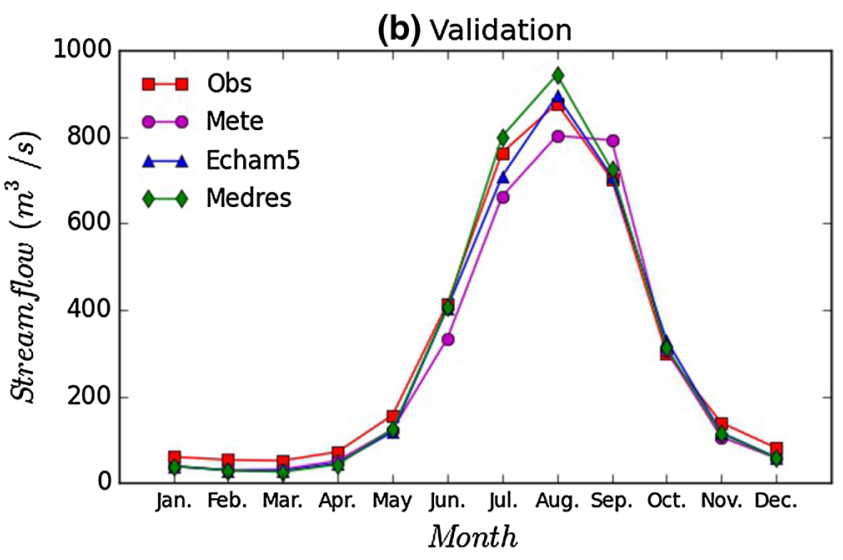

simulated streamflow based on Echam5 outputs, Mderes simulated streamflow based on Medres outputs)
Fig. 4 Average of hydrological variables represented by the VIC model for the period of 1981-2000 (mm)
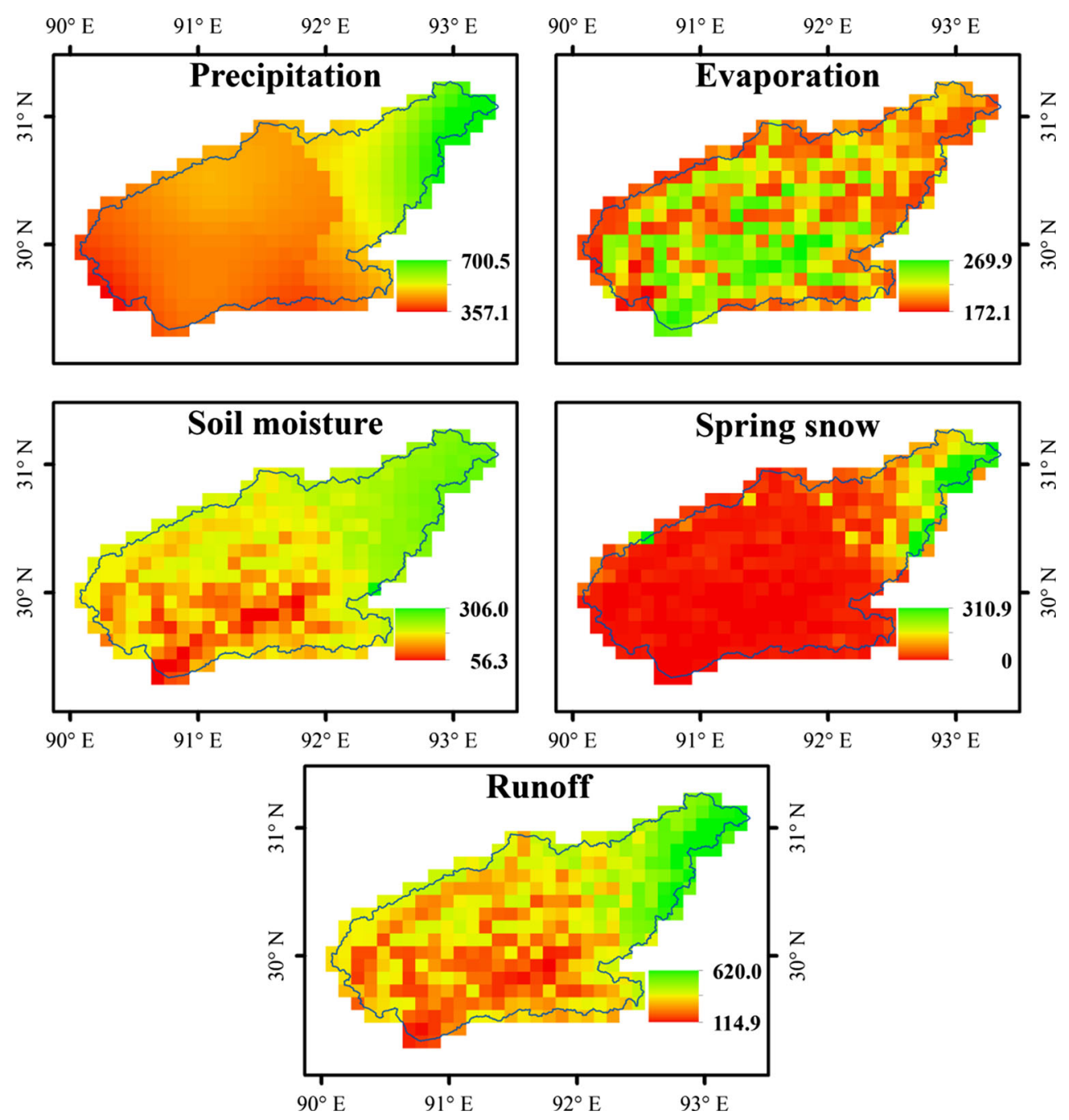

shows higher value of 0.72 in the downstream which implies more precipitation was used for evaporation in this region, but lower value of 0.11 in the upstream and

around the boundary where more precipitation was used to generate runoff. Greater values are found in the highelevation grids. 
Fig. 5 Simulated evaporation ratio and runoff ratio for the period of 1981-2000
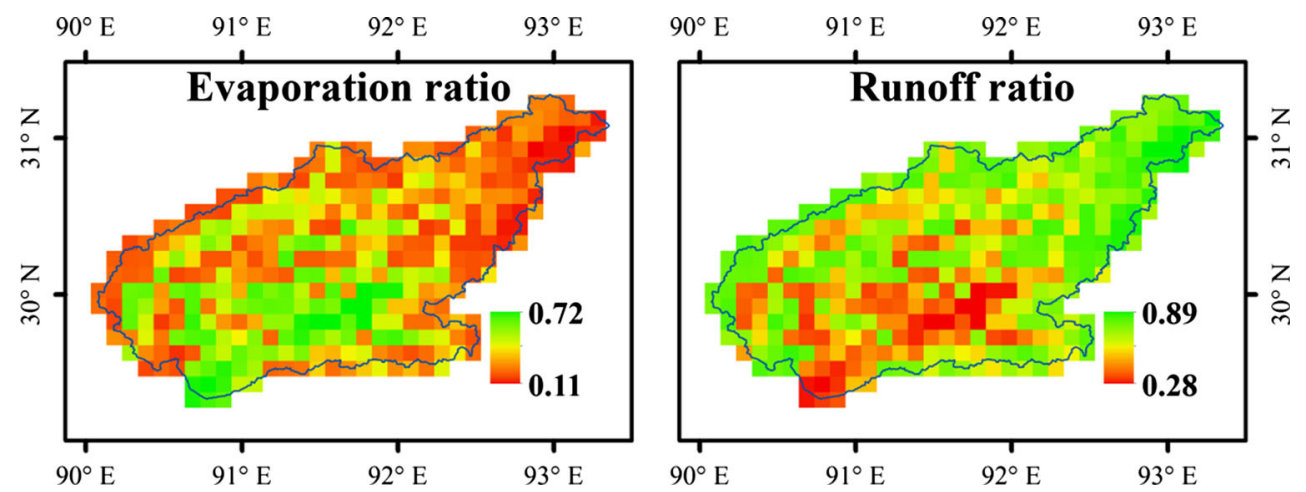

\section{Climate downscaling}

Table 3 documents the selected predictors and simulation results of the ASD model by using the ERA-40 re-analysis data at each station. The representation of temperature regimes is better than precipitation in terms of $R^{2}$, with the former greater than 0.90 , and latter between 0.13 and 0.22 . This is consistent with Hessami et al. (2008), where $R^{2}$ for precipitation is around the same range. Considering the low values of RMSD (smaller than 0.25 for precipitation and 0.015 for temperature), the performance of the ASD model in the LR basin is satisfactory. More details about the downscaling framework can be found in Liu et al. (2014).
After the regression function was formulated, it was then applied to the GCMs climate scenarios to generate the station-based climate variables. Figure 6 presents the magnitudes of change for precipitation and average temperature in term of differences between the future scenarios and the historical records for the years of 1981-2000. Monthly precipitation shows dramatic change for all scenarios. In July and August, precipitation may increase significantly with the largest value of $60 \%$ (Fig. 6a). However, from October to May the following year, precipitation will decrease largely, especially in November, February and March. At the annual scale, precipitation shows an increasing trend, varying from 5.89 to $20.09 \%$

Table 3 Simulation results of the ASD model at each station

\begin{tabular}{|c|c|c|c|c|c|c|}
\hline \multirow[t]{2}{*}{ Station } & \multicolumn{3}{|l|}{ Daily precipitation } & \multicolumn{3}{|c|}{ Daily average temperature } \\
\hline & Predictors no. & $\mathrm{R}^{2}$ & RMSD & Predictors no. & $\mathrm{R}^{2}$ & RMSD \\
\hline Chali & $1^{\mathrm{a}}, 8,9,16,19$ & 0.22 & 0.146 & $3,8,9,15,16$ & 0.91 & 0.008 \\
\hline Damshung & $3,7,13,15,19$ & 0.19 & 0.072 & $1,3,9,13,16$ & 0.91 & 0.006 \\
\hline Lhasa & $8,10,13,18,20$ & 0.14 & 0.096 & $1,3,9,13,16$ & 0.91 & 0.008 \\
\hline Nakechu & $7,8,9,11,18$ & 0.22 & 0.248 & $8,11,14,17,20$ & 0.91 & 0.013 \\
\hline Nyemo & $5,9,12,14,15$ & 0.13 & 0.094 & $1,3,9,13,16$ & 0.92 & 0.006 \\
\hline Zedang & $6,7,9,17,19$ & 0.15 & 0.097 & $1,3,9,13,19$ & 0.91 & 0.005 \\
\hline
\end{tabular}

${ }^{a}$ Numbers are predictors listed in Table 1

(a) Precipitation

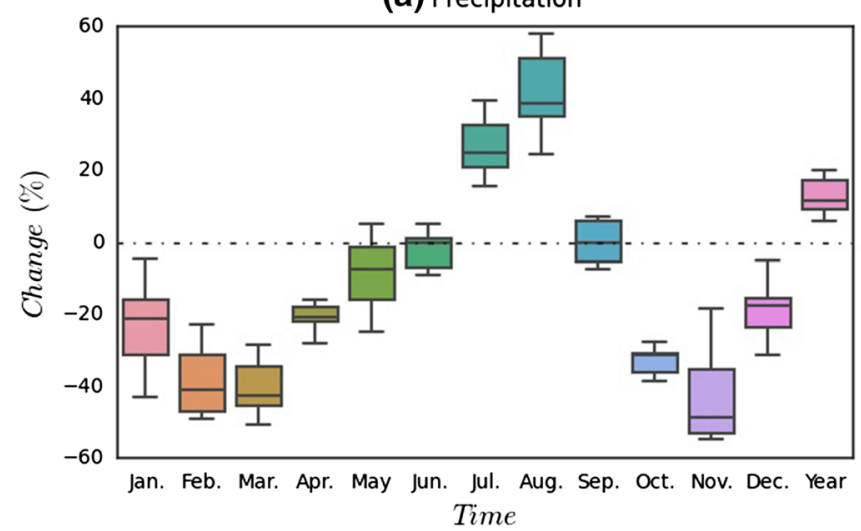

(b) Temperature

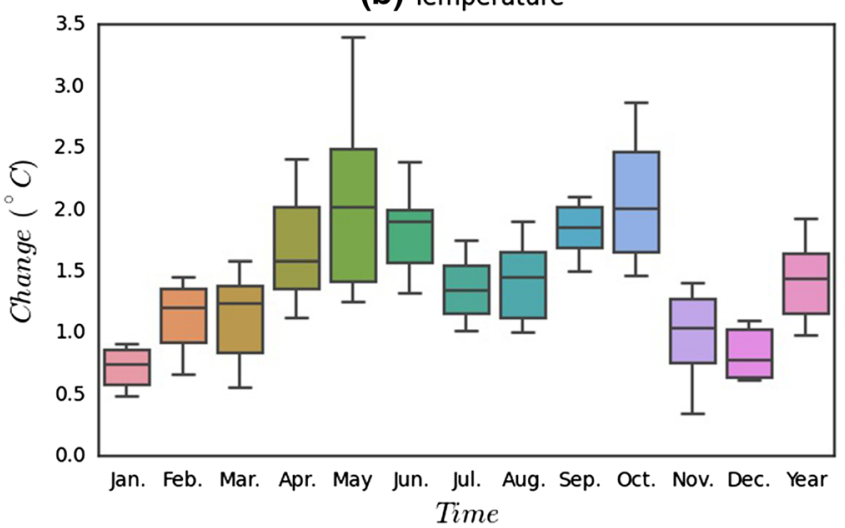

Fig. 6 Future climate change at the monthly and annual scales between 2046-2065 and 1981-2000 
Table 4 Scenarios of future climate for the period of 2046-2065

\begin{tabular}{|c|c|c|c|c|c|c|}
\hline \multirow[t]{2}{*}{ Variables } & \multicolumn{3}{|c|}{ Echam5 } & \multicolumn{3}{|c|}{ Medres } \\
\hline & A1B & $\mathrm{A} 2$ & B1 & A1B & A2 & B1 \\
\hline Daily precipitation (\%) & 10.10 & 9.09 & 5.89 & 18.67 & 20.09 & 13.04 \\
\hline Daily average temperature $\left({ }^{\circ} \mathrm{C}\right)$ & 1.45 & 1.06 & 0.98 & 1.93 & 1.71 & 1.43 \\
\hline Daily maximum temperature $\left({ }^{\circ} \mathrm{C}\right)$ & 2.84 & 2.15 & 2.01 & 3.51 & 3.23 & 2.67 \\
\hline Daily minimum temperature $\left({ }^{\circ} \mathrm{C}\right)$ & 0.75 & 0.54 & 0.44 & 0.77 & 0.70 & 0.57 \\
\hline
\end{tabular}

(Fig. 6; Table 4). A question arises as to how precipitation increases in the annual scale when most of months show declining trend. The reason seems to be that precipitation mainly occurs in summer (60-70\% of the annual amount), therefore, large increase in summer results in the increase of the annual precipitation. Additionally, the spatial change for annual precipitation is given in Fig. 7. The distribution presents a clear spatial variation. For Echam5, the change shows the similar spatial pattern with the historical precipitation, with a decreasing trend from the northeast part to the southwest part. Most of grids in the east region present an increase, but a decreasing trend is found in the west region. However, a distribution of increasing in north and decreasing in south is estimated by Medres.

Daily average temperature will increase largely for all scenarios, especially between April and October (Fig. 6b). This change implies the warming tendency in the LR basin. Daily maximum temperature will experience the largest warming trend with average value greater than $2^{\circ} \mathrm{C}$, whereas the magnitude of change for daily minimum temperature is not significant with an average about $0.6{ }^{\circ} \mathrm{C}$.

It is clear from the simulated results that uncertainties between different scenarios are significant. In order to obtain a reasonable and reliable range, it is necessary to include more GCMs under different scenarios to give a reliable range.

\section{Impacts of climate change on hydrological components}

\subsection{Evaporation}

Monthly evaporation shows dramatic temporal variation. A large drop of more than $25 \%$ is found from November to March the following year, while July and August will witness dramatic increase over $40 \%$ (Fig. 8a). However, no significant change of evaporation is found in other
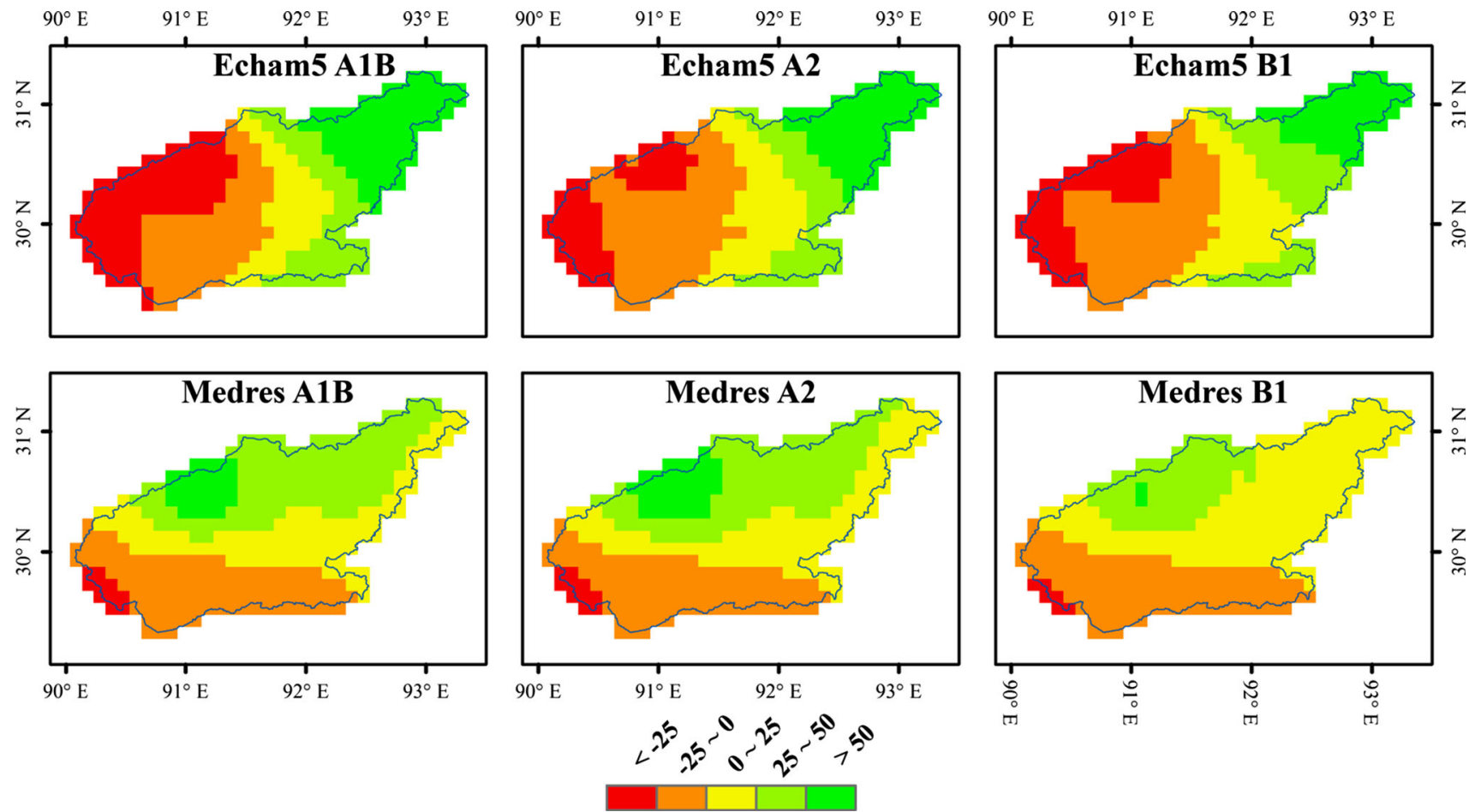

Fig. 7 Percentage change of annual precipitation between 2046-2065 and 1981-2000 (\%) 
(a) Evaporation

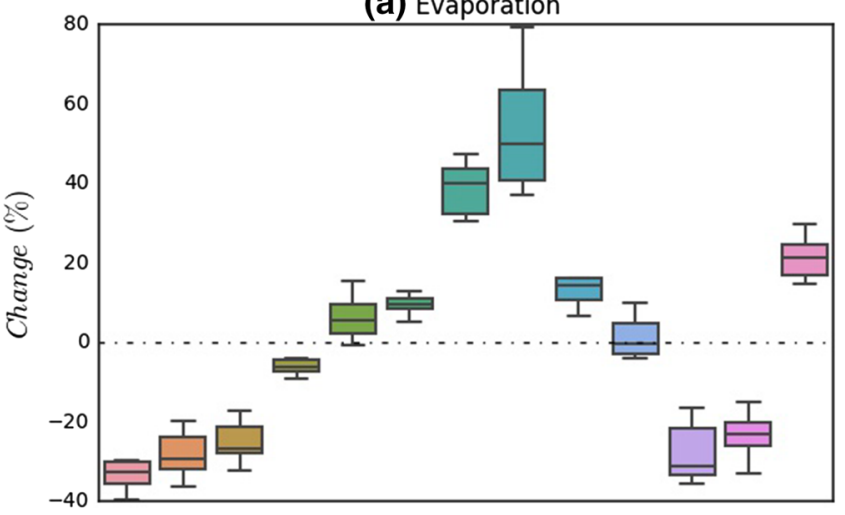

(c) Runoff

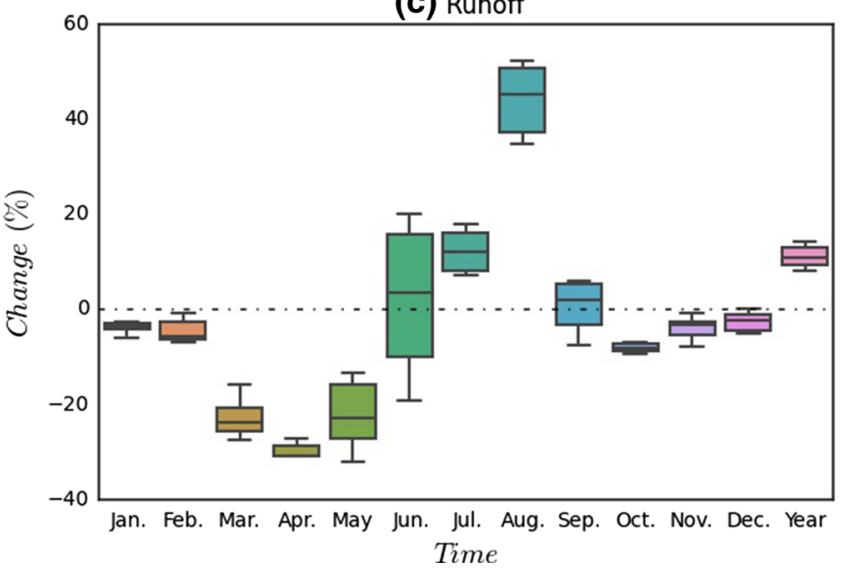

(b) Soil moisture

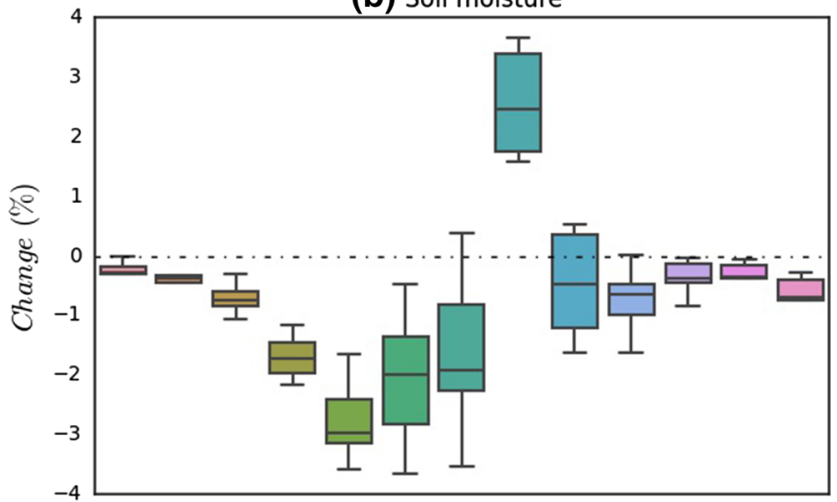

(d) Streamflow

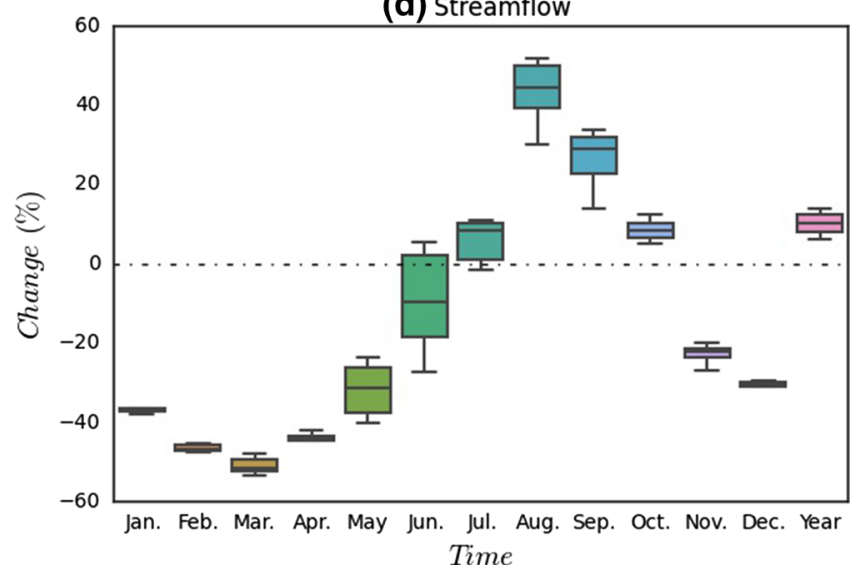

Fig. 8 Projected change of hydrological factors at the monthly and annual scales between 2046-2065 and 1981-2000

months. This kind of change pattern may be good for the agriculture due to the decrease of evaporation in the spring when crops need a large amount of water from the soil. At the annual scale, evaporation will increase with a median value of $29 \%$ (Fig. 8a).

Spatially, the increasing trend of annual evaporation is more dominant than decreasing, especially for the scenarios of Echam5 A1B, Medres A1B and Medres A2 in the northeastern part of the basin, where the magnitudes of change exceed $50 \%$ compared with the baseline (Fig. 9). Annual evaporation will change modestly in the middleand lower-stream regions within the range of $\pm 25 \%$ for all scenarios.

\subsection{Soil moisture}

All months show a decreasing trend for soil moisture in the future except August (Fig. 8b). Although the change is minor, it may still post challenge to agriculture and ecosystem duo to the decreases during the months between April and July when crops and vegetation need more water from the soil. Spatially, soil moisture only presents slight change with the similar spatial pattern as precipitation (Fig. 10). Regarding Echam5, three scenarios give a small rising tendency with a range of below $5 \%$ in the east part. An insignificant decrease appears in the west part. For Medres, slight increase is found in the northern part under three scenarios, whereas the decrease dominates the southern part.

\subsection{Spring snow cover}

Snowmelt contributes much water to the runoff for rivers in the TP (Immerzeel and Bierkens 2010a; Siderius et al. 2013; Zhang et al. 2013). Spring snowmelt plays an important role for the irrigation during the period of crop growth. The projection of spring snow cover in the LR basin shows a negative impacts since most of grids will experience dramatic decrease (Fig. 11). Spring snow cover may disappear in a large number of grids for all scenarios in the middle twenty-first century.

\subsection{Runoff}

Runoff in months from September to February the following year will change with a slight decrease within $10 \%$ (Fig. 8c). However, the magnitudes of decrease in spring are significant ranging from 20 to $40 \%$. In summer, most 

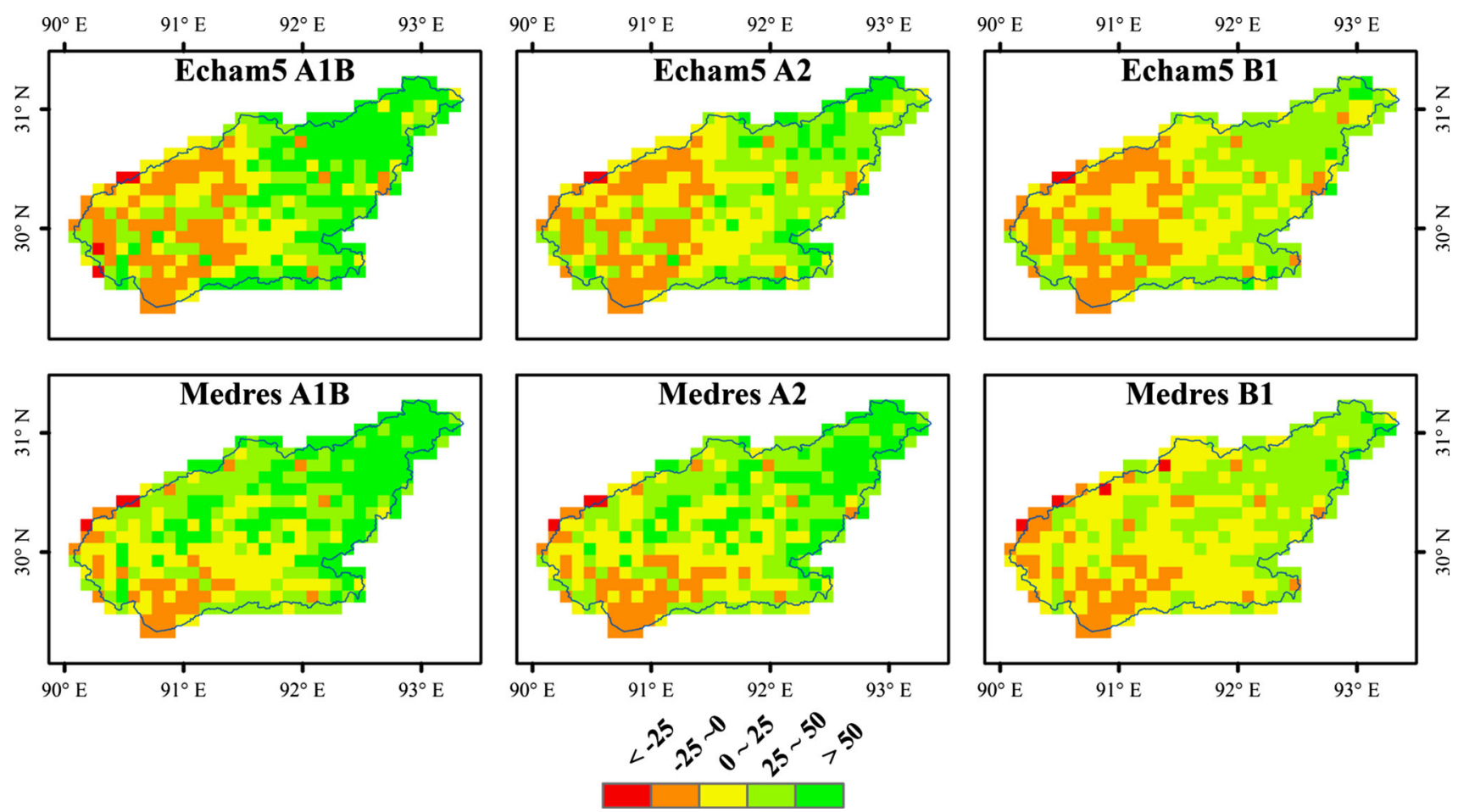

Fig. 9 Percentage change of annual evaporation between 2046-2065 and 198-2000 (\%)
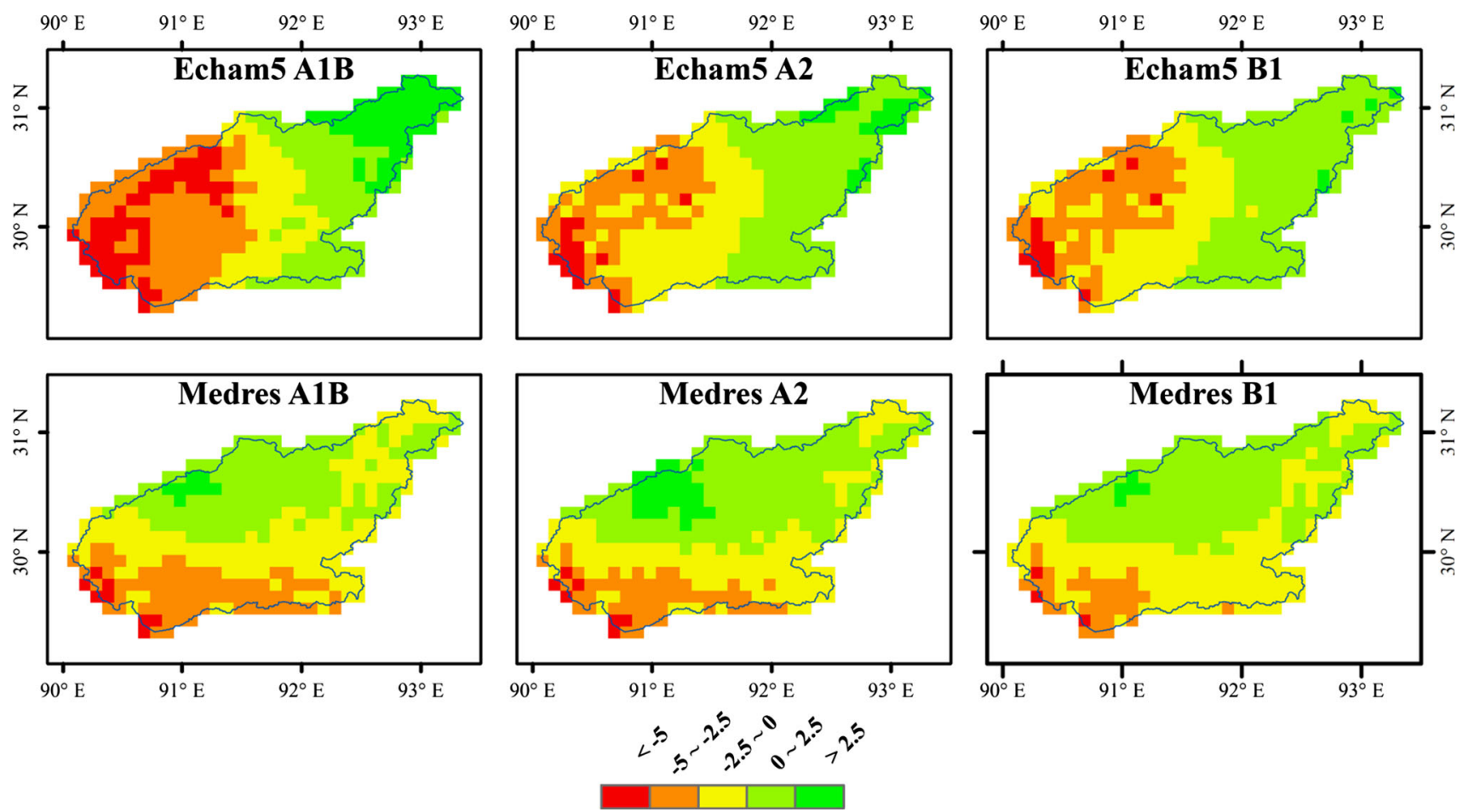

Fig. 10 Percentage change of annual soil moisture between 2046-2065 and 1981-2000 (\%)

of scenarios predict an upward tendency except that by Medres in June. The annual runoff will increase with low uncertainty.
Spatially, runoff shows a pronounced variation in the LR basin for all scenarios with the similar pattern as precipitation (Fig. 12). The change of runoff shows an increasing trend in 

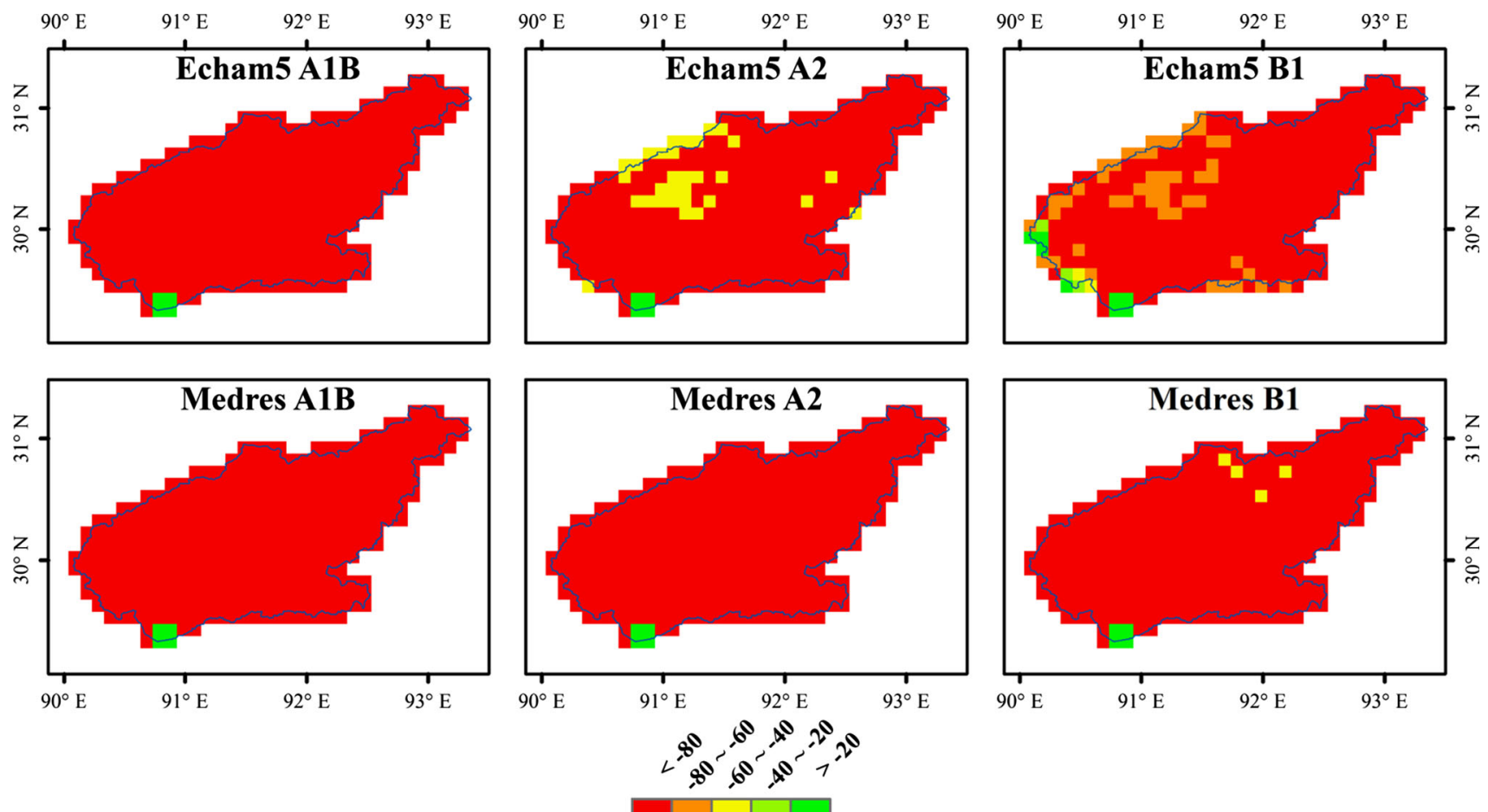

Fig. 11 Percentage change of spring snow cover between 2046-2065 and 1981-2000 (\%)
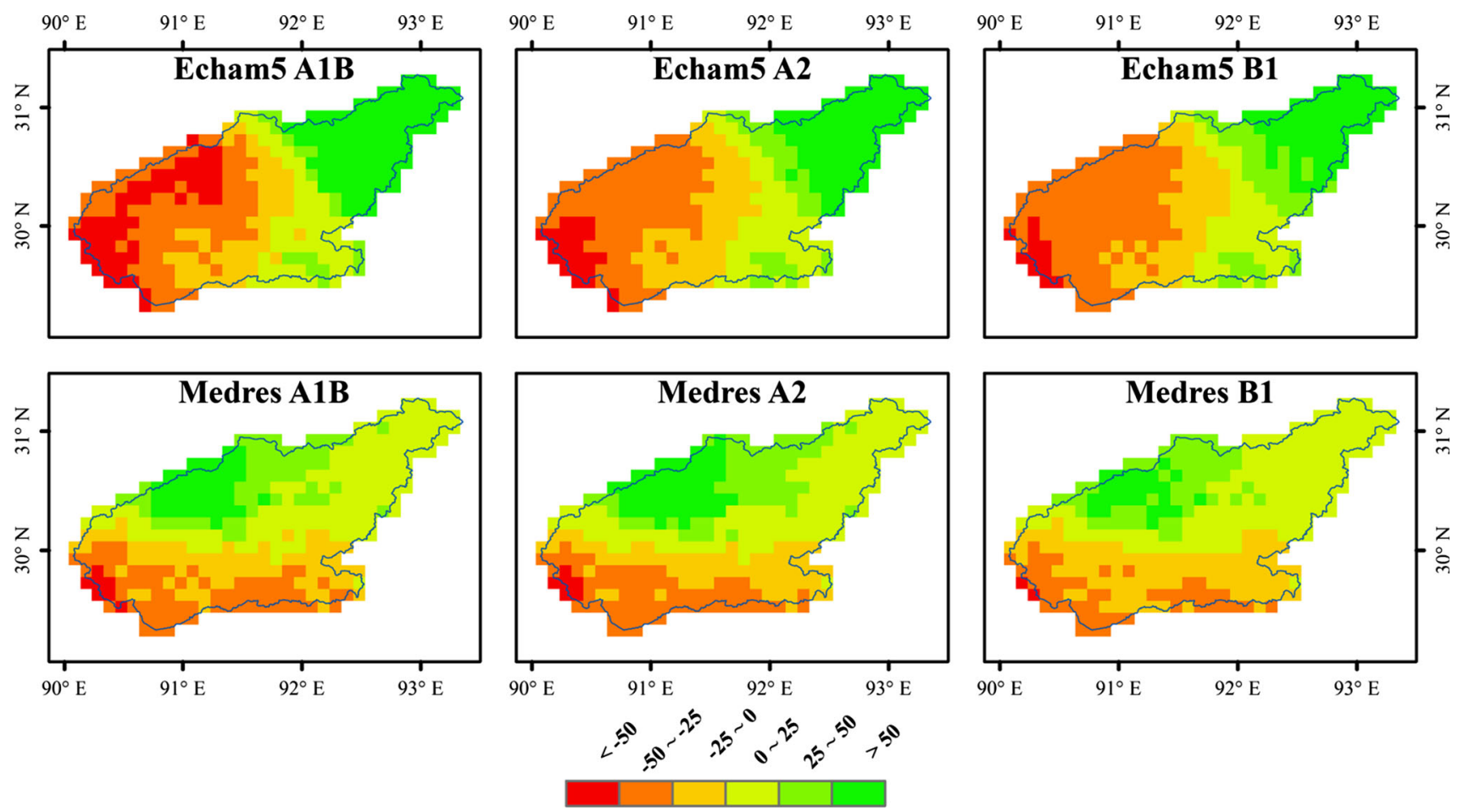

Fig. 12 Percentage change of annual runoff between 2046-2065 and 1981-2000 (\%)

the eastern part of the watershed with the largest magnitude of more than $50 \%$. In contrast, significant decline can be observed in the western part, especially for the scenario Echam5
A1B. Regarding Medres, about $60 \%$ grid cells located in the northern part show an upward trend, whereas the southern part gives a downward trend up to $50 \%$. 


\subsection{Streamflow}

River channel flow is the combined result of precipitation, evaporation, soil moisture, and snowmelt, etc. Change in these factors will result in change of the flow regime. Figure $8 \mathrm{~d}$ demonstrates a significant decrease of river flow in the Lhasa hydrological station from November to May the following year. In summer and autumn, significant increases will be expected, especially in August. Streamflow at the annual scale shows a slight increase with low uncertainty.

\section{Discussion}

\subsection{Comparison with other studies}

Several similar studies were carried out to investigate the impacts of climate change on hydrological processes in the headwater catchments of large river systems in the TP. Liu et al. (2009) projected the climate change impacts on evaporation and runoff in headwater catchment of the Tarim River basin by using the VIC model. A decreasing trend was detected for winter runoff, which may be resulted from the decreasing winter air temperature, as well as an increasing trend of spring runoff. Xu et al. (2009) applied the SWAT model to explore the impacts of climate change on streamflow in headwater catchment of the Yellow River. An overall decreasing trend of annual streamflow was found. The climate change impacts on hydrological processes in the upper reaches of the Yangtze River were also assessed by using EasyDHM with the climate scenarios provided by HadCM3 and Echam4 (Sun et al. 2013). It was found that the runoff may decline with the increasing temperature and decreasing annual rainfall. Compared with these studies, climate change may bring more negative impacts on hydrological processes in the LR basin than other river systems in the TP, with not only water scarcity but also floods. This may cause serious problems to the development of social-economics in the local region or even the whole Tibet.

\subsection{Implication of this study}

The simulation results imply that precipitation plays a central role in the formulation of hydrological processes in the LR basin from the temporal and spatial perspectives. This is consistent with the results reported by Zhang et al. (2013). They found that precipitation contributes $65.4 \%$ of annual runoff in the Brahmaputra River basin. There is a good temporal agreement between change patterns of precipitation and evaporation as well as runoff. Also, the spatial distribution of soil moisture and runoff matches well with precipitation. Therefore, a reliable prediction of future precipitation is essential for the purpose of obtaining a better estimation of climate change impacts.

The decrease of runoff in spring (from March to May) is much greater than that from October to February the following year, although the decreases of precipitation in these two periods are similar. This may be caused by the large decrease of spring snow cover (Lin et al. 2008), which is used for supplementing the runoff in the baseline period. The reduction of spring runoff driven by disappearing snow cover may bring negative impacts on agriculture and ecosystem, since crops and plants need a large amount of soil water (green water) and irrigation water (blue water) for growth. Spatially, the considerable decrease of runoff in the western (from Echam5) or southern part (from Medres) might affect the agricultural water consumption and crop growth. Meanwhile, large reduction of river channel flow from November to May the following year may cause difficulties to withdraw water for irrigation and domestic water uses, whereas more critical floods will be expected during the summer, especially in August.

\subsection{Limitation of this study}

In this study, outputs of two GCMs from IPCC AR4 were adopted to project the impacts of climate change in the LR basin. So far, however, simulation results from IPCC AR5 are available from the Internet. It may be helpful to use the new climate scenarios from Representative Concentration Pathways (RCPs) (Meinshausen et al. 2011) rather than the SRES for improved knowledge and skills in estimating the future climate conditions. But, it is still important to report the impacts of climate change under the SRES framework in order to take a comparison with the simulation results derived from the IPCC AR5 outputs, considering the huge uncertainties involved in the projection of future climate and the scarcity of studies in this area.

The YZR is an important international river and plays a crucial role in providing water resources and maintaining ecosystem health not only for China but also for downstream countries, such as India and Bangladesh. It is important to investigate the climate change impacts on hydrological cycle, water resources and ecosystem with a perspective of the whole basin. The study is the first step of this work. In the next step, we plan to expand the study area to the whole YZR basin.

\section{Conclusion}

Climate change is projected to exert significant impacts on hydrological cycle and water availability, and consequently on agriculture and ecosystem systems in the TP. The VIC 
model coupled with SCE-UA was applied to quantify the impacts of climate change from the spatial and temporal perspectives in the middle of twenty-first century, taking the LR basin as a case study. Future climate datasets were generated by downscaling two GCMs under SRES A1B, $\mathrm{A} 2$, and $\mathrm{B} 1$ scenarios.

The VIC model satisfactorily reproduced the main characteristics of observed streamflow in terms of low relative errors and good agreement between observed and simulated flow series. The simulation results describe the spatio-temporal distribution with great variations for major hydrological variables. Temperature in the future may increase significantly, especially for daily maximum temperature with a value of more than $2{ }^{\circ} \mathrm{C}$. Annual precipitation shows a slight increase, but monthly precipitation is likely to vary significantly, with a sharp increase in summer while dramatic decreases in other three seasons.

Spatially, spring snow cover will decrease tremendously. At the same time, the change of evaporation and runoff is conspicuous and the variations are substantial within the whole basin. On the temporal dimension, evaporation will rise with the magnitudes ranging from 14.89 to $29.71 \%$ at the annual scale. The change of annual runoff and flow is comparable with the range being 8.26-14.23 and $6.04-13.92 \%$, respectively. However, the monthly change patterns are inconsistent, with rising trend in summer but reducing in other three seasons.

The significant spatio-temporal change of hydrological processes caused by climate change may greatly influence the potential water resources availability and agricultural production as well as ecosystem functions in the LR basin. Therefore, it's important to take measures to mitigate the adverse impacts and adapt to the changing environment. The results obtained in this study will be expected to serve as a reference for future water resources management and climate change mitigation and adaptation.

Acknowledgements This study was supported by the Fundamental Research Funds for the Central Universities (Grant No. 2009SC-5). China Meteorological Data Sharing Service System (http://cdc.cma. gov.cn/) is greatly appreciated for providing meteorological data used in this study.

\section{References}

Barnett TP, Adam JC, Lettenmaier DP (2005) Potential impacts of a warming climate on water availability in snow-dominated regions. Nature 438:303-309. doi:10.1038/nature04141

Bolch T, Kulkarni A, Kaab A, Huggel C, Paul F, Cogley JG, Frey H, Kargel JS, Fujita K, Scheel M, Bajracharya S, Stoffel M (2012) The state and fate of Himalayan Glaciers. Science 336:310-314. doi:10.1126/science. 1215828

Brown ME, Funk CC (2008) Food security under climate change. Science 319:580-581. doi:10.1126/science. 1154102
Casado MJ, Pastor MA (2011) Use of variability modes to evaluate AR4 climate models over the Euro-Atlantic region. Clim Dyn 38:225-237. doi:10.1007/s00382-011-1077-2

Duan QY, Gupta VK, Sorooshian S (1993) Shuffled complex evolution approach for effective and efficient global minimization. J Optim Theory Appl 76:501-521. doi:10.1007/Bf00939380

Duan QY, Sorooshian S, Gupta VK (1994) Optimal use of the SCE-UA global optimization method for calibrating watershed models. J Hydrol 158:265-284. doi:10.1016/0022-1694(94)90057-4

Fu GB, Liu ZF, Charles SP, Xu ZX, Yao ZJ (2013) A score-based method for assessing the performance of GCMs: a case study of southeastern Australia. J Geophys Res 118:4154-4167. doi:10. 1002/jgrd.50269

Guan ZH, Chen CY, Ou YX, Fan YQ, Zhang YS, Chen ZM, Bao SH, $\mathrm{Zu}$ YT, He XW, Zhang MT (1984) Rivers and lakes in Tibet. Science and Technology Press, Beijing (in Chinese)

Guo DL, Wang HJ, Li D (2012) A projection of permafrost degradation on the Tibetan Plateau during the 21st century. J Geophys Res. doi:10.1029/2011jd016545

Hessami M, Gachon P, Ouarda TBMJ, St-Hilaire A (2008) Automated regression-based statistical downscaling tool. Environ Model Softw 23:813-834. doi:10.1016/j.envsoft.2007.10.004

Hostetler SW, Bartlein PJ, Clark PU, Small EE, Solomon AM (2000) Simulated influences of Lake Agassiz on the climate of central North America 11,000 years ago. Nature 405:334-337. doi:10. 1038/35012581

Immerzeel WW, Bierkens MFP (2010) Seasonal prediction of monsoon rainfall in three Asian river basins: the importance of snow cover on the Tibetan Plateau. Int J Climatol 30:1835-1842. doi: $10.1002 /$ joc. 2033

Immerzeel WW, van Beek LP, Bierkens MF (2010) Climate change will affect the Asian water towers. Science 328:1382-1385. doi: $10.1126 /$ science. 1183188

IPCC (2000) Special report on emissions scenarios: a special report of Working Group III to the fourth assessment report of the intergovernmental panel on climate change. Cambridge University Press, Cambridge

Ji Z, Kang S (2013) Projection of snow cover changes over China under RCP scenarios. Clim Dyn 41:589-600. doi:10.1007/ s00382-012-1473-2

Ju H, van der Velde M, Lin ED, Xiong W, Li YC (2013) The impacts of climate change on agricultural production systems in China. Clim Change 120:313-324. doi:10.1007/s10584-013-0803-7

Kang SC, Xu YW, You QL, Flugel WA, Pepin N, Yao TD (2010) Review of climate and cryospheric change in the Tibetan Plateau. Environ Res Lett. doi:10.1088/1748-9326/5/1/015101

Li X, Cheng GD, Lu L (2003) Comparison study of spatial interpolation methods of air temperature over Qinghai-Xizang Plateau. Plateau Meteorol 22:565-574 (in Chinese)

Li FP, Xu ZX, Feng YC, Liu M, Liu WF (2012) Changes of land cover in the Yarlung Tsangpo River basin from 1985 to 2005. Environ Earth Sci 68:181-188. doi:10.1007/s12665-012-1730-Z

Li FP, Zhang YQ, Xu ZX, Teng J, Liu CM, Liu WF, Mpelasoka F (2013) The impact of climate change on runoff in the southeastern Tibetan Plateau. J Hydrol 505:188-201. doi:10. 1016/j.jhydrol.2013.09.052

Li FP, Xu ZX, Liu WF, Zhang YQ (2014) The impact of climate change on runoff in the Yarlung Tsangpo River basin in the Tibetan Plateau. Stoch Environ Res Risk Assess 28:517-526. doi:10.1007/s00477-013-0769-Z

Liang X, Xie ZH (2001) A new surface runoff parameterization with subgrid-scale soil heterogeneity for land surface models. Adv Water Resour 24:1173-1193. doi:10.1016/S03091708(01)00032-X

Liang X, Lettenmaier DP, Wood EF, Burges SJ (1994) A simple hydrologically based model of land-surface water and energy 
fluxes for general-circulation models. J Geophys Res 99:14415-14428. doi:10.1029/94jd00483

Liang X, Lettenmaier DP, Wood EF (1996a) One-dimensional statistical dynamic representation of subgrid spatial variability of precipitation in the two-layer variable infiltration capacity model. J Geophys Res 101:21403-21422. doi:10.1029/96jd01448

Liang X, Wood EF, Lettenmaier DP (1996b) Surface soil moisture parameterization of the VIC-2L model: evaluation and modification. Glob Planet Change 13:195-206. doi:10.1016/09218181(95)00046-1

Lin X, Zhang Y, Yao Z, Gong T, Wang H, Chu D, Liu L, Zhang F (2008) The trend on runoff variations in the Lhasa River Basin. J Geogr Sci 18:95-106. doi:10.1007/s11442-008-0095-4

Liu ZF, Xu ZX, Huang JX, Charles SP, Fu GB (2009) Impacts of climate change on hydrological processes in the headwater catchment of the Tarim River basin, China. Hydrol Process 24:196-208. doi:10.1002/hyp.7493

Liu WF, Xu ZX, Li FP, Qiu LH (2013) GCM performance on simulating climatological factors in Yarlung Zangbo River basin based on a ranked score method. J Beijing Normal Univ (Nat Sci) 49:304-311 (in Chinese)

Liu WF, Xu ZX, Li FP, Su LQ (2014) Climate change scenarios in the Yarlung Zangbo river basin based on the ASD model. Plateau Meteorol 33:26-36 (in Chinese)

Meinshausen M, Smith SJ, Calvin K, Daniel JS, Kainuma MLT, Lamarque JF, Matsumoto K, Montzka SA, Raper SCB, Riahi K, Thomson A, Velders GJM, van Vuuren DPP (2011) The RCP greenhouse gas concentrations and their extensions from 1765 to 2300. Clim Change 109:213-241. doi:10.1007/s10584-0110156-Z

Piao S, Ciais P, Huang Y, Shen Z, Peng S, Li J, Zhou L, Liu H, Ma Y, Ding Y, Friedlingstein P, Liu C, Tan K, Yu Y, Zhang T, Fang J (2010) The impacts of climate change on water resources and agriculture in China. Nature 467:43-51. doi:10.1038/nature09364

Prasch M, Weber M, Mauser W (2011) Distributed modelling of snow- and ice-melt in the Lhasa River basin from 1971 to 2080. In: Cold regions hydrology in a changing climate, Proceedings of symposium H02, vol 346. IAHS Publication, Wallingford, pp 57-64

Qiu J (2008) The third pole. Nature 454:393-396. doi:10.1038/ $454393 \mathrm{a}$

Qiu LH, You JJ, Qiao F, Peng DZ (2014) Simulation of snowmelt runoff in ungauged basins based on MODIS: a case study in the Lhasa River basin. Stoch Environ Res Risk Assess. doi:10.1007/ s00477-013-0837-4

Siderius C, Biemans H, Wiltshire A, Rao S, Franssen WH, Kumar P, Gosain AK, van Vliet MT, Collins DN (2013) Snowmelt contributions to discharge of the Ganges. Sci Total Environ 468:S93-S101. doi:10.1016/j.scitotenv.2013.05.084

Sivakumar B (2011) Global climate change and its impacts on water resources planning and management: assessment and challenges. Stoch Environ Res Risk Assess 25:583-600. doi:10.1007/ s00477-010-0423-y

Sridhar V, Jin X, Jaksa WTA (2012) Explaining the hydroclimatic variability and change in the Salmon River basin. Clim Dyn 40:1921-1937. doi:10.1007/s00382-012-1467-0

Su FG, Xie ZH (2003) A model for assessing effects of climate change on runoff in China. Prog Nat Sci 13:701-707. doi:10. $1080 / 10020070312331344270$
Sun JL, Lei XH, Tian Y, Liao WH, Wang YH (2013) Hydrological impacts of climate change in the upper reaches of the Yangtze River Basin. Quatern Int 304:62-74. doi:10.1016/j.quaint.2013. 02.038

Trenberth KE (1997) The use and abuse of climate models. Nature 386:131-133. doi:10.1038/386131a0

Uppala SM, Kallberg PW, Simmons AJ, Andrae U, Bechtold VD, Fiorino M, Gibson JK, Haseler J, Hernandez A, Kelly GA, Li X, Onogi K, Saarinen S, Sokka N, Allan RP, Andersson E, Arpe K, Balmaseda MA, Beljaars ACM, Van De Berg L, Bidlot J, Bormann N, Caires S, Chevallier F, Dethof A, Dragosavac M, Fisher M, Fuentes M, Hagemann S, Holm E, Hoskins BJ, Isaksen L, Janssen PAEM, Jenne R, McNally AP, Mahfouf JF, Morcrette JJ, Rayner NA, Saunders RW, Simon P, Sterl A, Trenberth KE, Untch A, Vasiljevic D, Viterbo P, Woollen J (2005) The ERA-40 re-analysis. Q J R Meteorol Soc 131:2961-3012. doi:10.1256/Qj. 04.176

Viney NR, Perraud JM, Vaze J, Chiew FHS, Post DA, Yang A (2009) The usefulness of bias constraints in model calibration for regionalization to ungauged catchments. In: Interfacing modelling and simulation with mathematical and computational sciences, 18th World IMACS Congress and MODSIM09 international congress on modelling and simulation, pp 3421-3427

Wang X, Yang T, Shao Q, Acharya K, Wang W, Yu Z (2013) Statistical downscaling of extremes of precipitation and temperature and construction of their future scenarios in an elevated and cold zone. Stoch Environ Res Risk Assess 26:405-418. doi:10.1007/s00477-011-0535-Z

West AJ (2008) Geomorphology: mountains and monsoons. Nat Geosci 1:814-815. doi:10.1038/Ngeo369

Wu G, Mao J, Duan A, Zhang Q (2006) Current progresses in study of impacts of the Tibetan Plateau on Asian Summer Climate. Acta Meteorol Sin 20:144-158

Xie H, Zhu X (2013) Reference evapotranspiration trends and their sensitivity to climatic change on the Tibetan Plateau (1970-2009). Hydrol Process 27:3685-3693. doi:10.1002/hyp. 9487

Xie ZH, Su FG, Liang X, Zeng QC, Hao ZC, Guo YF (2003) Applications of a surface runoff model with Horton and Dunne runoff for VIC. Adv Atmos Sci 20:165-172

Xu ZX, Gong TL, Li JY (2008) Decadal trend of climate in the Tibetan Plateau-regional temperature and precipitation. Hydrol Process 22:3056-3065. doi:10.1002/hyp.6892

Xu ZX, Zhao FF, Li JY (2009) Response of streamflow to climate change in the headwater catchment of the Yellow River basin. Quatern Int 208:62-75. doi:10.1016/j.quaint.2008.09.001

Yao T, Li Z, Yang W, Guo X, Zhu L, Kang S, Wu Y, Yu W (2010) Glacial distribution and mass balance in the Yarlung Zangbo River and its influence on lakes. Chin Sci Bull 55:2072-2078. doi:10.1007/s11434-010-3213-5

You Q, Kang S, Wu Y, Yan Y (2007) Climate change over the Yarlung Zangbo River Basin during 1961-2005. J Geog Sci 17:409-420. doi:10.1007/s11442-007-0409-y

Zhang LL, Su FG, Yang DQ, Hao ZC, Tong K (2013) Discharge regime and simulation for the upstream of major rivers over Tibetan Plateau. J Geophys Res 118:8500-8518. doi:10.1002/ Jgrd.50665

Zhao RJ (1992) The Xinanjiang model applied in China. J Hydrol 135:371-381 